\title{
Piroxicam-Collagen-Based Sponges for Medical Applications
}

\author{
Daniel-Cristian Ioan, ${ }^{1}$ Ileana Rău $\mathbb{D},{ }^{1}$ Grațiela Teodora Tihan $\left(\mathbb{D},{ }^{1}\right.$ \\ Roxana Gabriela Zgârian $\mathbb{D}^{1},{ }^{1}$ Mihaela Violeta Ghica, ${ }^{2}$ Mădălina Georgiana Albu Kaya $\mathbb{D}^{3}{ }^{3}$ \\ and Elena Cristina Dinu-Pîrvu ${ }^{2}$ \\ ${ }^{1}$ University Politehnica of Bucharest, Faculty of Applied Chemistry and Materials Science, General Chemistry Department, \\ 1-7 Gh. Polizu Str., 011061 Bucharest, Romania \\ "Carol Davila" University of Medicine and Pharmacy, Faculty of Pharmacy, Physical and Colloidal Chemistry Department, 6 Traian \\ Vuia Str., 020956 Bucharest, Romania \\ ${ }^{3}$ INCDTP-Division Leather and Footwear Research Institute, Collagen Department, 93 Ion Minulescu Str., \\ 031215 Bucharest, Romania
}

Correspondence should be addressed to Ileana Rău; ileana_brandusa@yahoo.com and Roxana Gabriela Zgârian; zgirianroxana@yahoo.com

Received 19 September 2018; Revised 20 January 2019; Accepted 4 March 2019; Published 29 May 2019

Guest Editor: Patrizia Paolicelli

Copyright (c) 2019 Daniel-Cristian Ioan et al. This is an open access article distributed under the Creative Commons Attribution License, which permits unrestricted use, distribution, and reproduction in any medium, provided the original work is properly cited.

\begin{abstract}
Depending on the concentration of the drug and/or the method of administration, drugs could be used in various ways. To take full advantage of the drug beneficial properties in oral medical interventions but also in other types of surgery, like plastic surgery, general surgery, or gynecological surgery, the drug concentration as well as the administration method itself will depend on the wound, type of surgery, and severity of the postoperative pain which can be very different. Generally, the local administration methods are recommended. Piroxicam, a nonsteroidal anti-inflammatory drug (NSAID) of the oxicam class, is generally used to relieve the symptoms of pain and inflammation. Starting from the idea of the special benefit of the interference between collagen-based materials and drug beneficial properties, our work was focused on the synthesis and characterization of new collagen-piroxicam materials. These new collagen-based materials present a good water absorption, and the piroxicam release suggests a biphasic drug release profile whereas the obtained values for the release exponent revealed a complex release mechanism including swelling, diffusion, and erosion.
\end{abstract}

\section{Introduction}

Pain represents a high and problematic symptom after any kind of surgery all over the world irrespective of the surgery type, wound dimensions, or the associated pathology of the patient. The current researches in medicine are based on the ongoing development of any potential cures for solving the needs of the patient; the main goal is to reduce and relieve the pain, the inflammation, and the sensation and to heighten the recovery process. All these aspects will contribute to the improvement of patient life quality; this is one of the main reasons for the use of a variety of medication in chronic and acute pain treatment $[1,2]$.
Piroxicam, an NSAID of the oxicam class of antiinflammatory drugs, represents a very viable option in pain management. The recent researches in the last decade show that when oral administration of this drug may have negative side effects, one of the usual effects is due to piroxicam gastrotoxicity. When the drug is applied locally, it may be able to bypass this undesired side effect. The recent researches show that by embedding the piroxicam in different types of delivery systems, like gels, scaffolds, polymer-based nanoparticles, liposomes, and even topical, intraligamentary, or intramuscular injection through dermal delivery, the negative gastrointestinal effect may be avoided and at the same time the systemic exposure of the drug is reduced. In this way, 
the various negative aspects of the piroxicam are practically reduced. The recent comparative studies on patients with postoperative pain and edema following maxillofacial surgery demonstrated that the NSAID local application represents a better solution by reducing the swelling and the pain in few days [3-7]. According to Desjardins' study [8], piroxicam drug lasts significantly longer (24 hours) and has a better effect compared to aspirin. Because the drug is concentrated in the tissues, local application of piroxicam has also a local analgesic effect, especially in the first few hours after the intervention [9].

One of the main objectives for the use of a wound dressing is the acceleration of the wound healing process. Collagen-based biomaterials are usually the most commonly used biomaterials in the bioengineering of the skin, connective tissue, mucosal tissue (oral and vaginal tissues and even organic tissue), and also in nerve and tendon tissue representing an alternative solution to various types of grafts as wound dressing after surgical defects that occur after removal of benign or premalignant lesions/tumors or reactive proliferations and incisional biopsy lesions. Collagen has some big advantages including resilience, suppleness, dressing property of mimicking the surrounding tissues, and a very good tolerance by tissue itself. It also acts as a strong mechanical barrier, and it helps in hemostasis, relieving pain, and preventing excessive contracture [10-13].

The use of collagen in various forms goes back millennia, but the main collagen application remains for burns and wound cover dressings, alveolar filling, antithrombogenic surfaces, wound healing process speeding, implant therapy by preventing epithelial migration, and allowing cells to regenerate. Collagen sponges when used in burns and ulcers (decubitus ulcers) have the ability to absorb large quantities of tissue exudates, blood, and saliva and present the benefit to adhere to the wet wounds and by clouting to facilitate the dermal and epidermal wound healing. Piroxicamcollagen sponges could also be used as the delivery system for intravaginal wounds or cervical dysplasia [14-18].

Collagen-based biomaterials can be applied in various dental surgeries and dental medicine, including wound dressing and hemostatic abilities, being a biomaterial that can easily help in GTR (guided tissue regeneration) [13]. In maxillofacial surgery, the mix between collagen and NSAIDs represents a very viable option. For example, after removal of an impacted third molar, one of the most frequent procedures in oral and maxillofacial surgery, usually followed by pain, swelling, and trismus (restricted jaw movements) [5], such collagen-based materials could be beneficial. The adhesion between the tissue and the piroxicam-collagen based biomaterial, the mucoadhesion, represents that state where two or more than two elements (from which at least one is biological) may adhere to each other for extended periods of time. The mucoadhesion offers the opportunity to release the drug through different routes of administration like ocular, nasal, vaginal, oral and in some cases intraligamentary, which is a more efficient and safer way of drug administration compared to oral administration $[19,20]$.

In this paper, piroxicam-collagen-based sponges are studied due to several reasons: (i) Local pain is one of the most critical points of patient care in medicine. Therefore, a drug use is mandatory and piroxicam, an NSAID, is a drug used for local pain management where the anti-inflammatory and analgesic effects are beneficial besides the basic commonly used treatment

(ii) The need to create a local delivery system that bypasses the systemic unwanted toxic side effects

(iii) Collagen sponges are a very high biocompatible and biodegradable biomaterial. At the same time, they are also well known for their safe and wellcharacterized supports as drug delivery systems [21-24]

The aim of this study was to obtain materials based on collagen and piroxicam for biomedical purposes, especially for various types of surgeries. The stability of collagenpiroxicam sponges was assured by glutaraldehyde as a cross-linking agent. Water absorption and enzymatic degradation tests were performed. At the same time, the piroxicam release from cross-linked collagen spongious forms was investigated and the kinetic mechanism was discussed.

\section{Materials and Methods}

Type I fibrillar collagen was obtained using the bovine hide, and, currently, technology from our laboratory (INCDTPDivision Leather and Footwear Research Institute, Collagen Department) was employed. Collagen can be obtained using two main technologies: molecular technology and/or fibrillar technology. In order to obtain molecular collagen, a proteolitic enzyme is used to cleave telopeptides. In this study, we used fibrillar technology to obtain type I collagen by alkaline treatment of bovine dermis with $5-10 \%$ sodium hydroxide and $1 \mathrm{M}$ sodium sulphate at room temperature for 2 days in order to remove telopeptidic nonhelical regions. Alkaline treatment was followed by an acidic one with $1 \mathrm{~N} \mathrm{HCl}$, and total solubilization of collagen in the undenatured state was performed. The salt precipitation and resolubilisation were carried out in order to purify collagen [25-27]. Collagen in the form of gel was obtained, and its concentration of $2.82 \%(w / v)$ was determined by gravimetric methods (dried at $\left.105^{\circ} \mathrm{C}\right)$.

Piroxicam drugs were obtained from Alfa Aesar whereas glutaraldehyde, used as a cross-linking agent, was purchased from Merck.

The concentration of the collagen gel was adjusted from concentration of $2.82 \%$ and acidic $\mathrm{pH}$ to concentration of $1 \%$ and $7.4 \mathrm{pH}$ using $1 \mathrm{M}$ sodium hydroxide. The piroxicam (solution) was added to the collagen gel in concentration of $1.0 \%, 1.5 \%$, and $2.0 \%$ (with respect to the dry collagen), and the obtained gels were cross-linked with $0.5 \%$ glutaraldehyde (solution) reported to dry collagen. The cross-linked gels were kept 24 hours at $4^{\circ} \mathrm{C}$ and then freeze-dried using a Delta 2-24 LSC lyophilizer (Martin Christ, Germany) as follows: the gels casted into glass Petri dishes were initially frozen at $-40^{\circ} \mathrm{C}$ during 12 hours followed by main freeze-drying at $-40^{\circ} \mathrm{C}$ and 0.1 mbar for 8 hours. Then, the temperature 


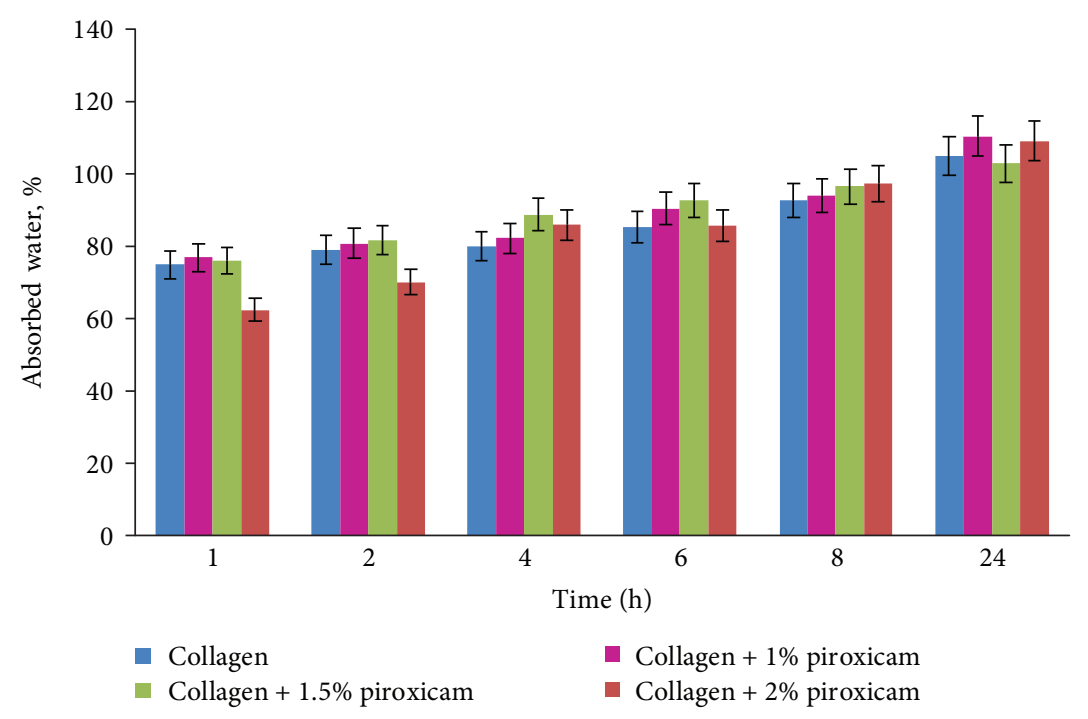

FIGURE 1: Water absorption of piroxicam sponges.

increases in steps to $10^{\circ} \mathrm{C}$ during 8 hours, to $20^{\circ} \mathrm{C}$ during another 8 hours, and to $30^{\circ} \mathrm{C}$ for 8 hours at same pressure, 0.1 mbar. The final freeze-drying lasted 4 hours: 1 hour at $30^{\circ} \mathrm{C}$ and $0.001 \mathrm{mbar}$ followed by 3 hours until temperature reached $35^{\circ} \mathrm{C}$. After 48 hours of freeze-drying, the collagen sponges were obtained and then characterized as we described below.

The water absorption tests were performed on collagen sponge half-cubes of $1 \mathrm{~cm} \times 1 \mathrm{~cm} \times 0.5 \mathrm{~cm}$ immersed in distilled water at $25^{\circ} \mathrm{C}$. Water absorption was calculated at different periods of time using equation (1). Every test was performed in triplicate.

$$
\% \text { water absorption }=\frac{w_{1}-w_{0}}{w_{0}} \times 100 \text {, }
$$

where $w_{0}$ is the dry mass and $w_{1}$ is the wet mass.

Enzymatic degradation test was performed using collagenase of Clostridium histolyticum from Sigma-Aldrich (USA) and a phosphate-buffered saline (PBS) solution with $\mathrm{pH}$ 7.4. Sponges with a known weight were immersed in PBS solution and incubated at $37^{\circ} \mathrm{C}$ overnight. Collagenase $(10 \mu \mathrm{g} / \mathrm{mL})$ was then added, and the test tube was replaced at $37^{\circ} \mathrm{C}$. At different time intervals, the degradation was interrupted by removing the scaffold from the degradation solution, squeezing, and weighting again the sponges. The mass loss percentage was calculated as follows:

$$
\% \text { collagen mass degraded }=\frac{w_{i}-w_{t}}{w_{i}} \times 100,
$$

where $w_{i}$ is the initial mass and $w_{t}$ is the mass after time $t$. Each biodegradation test was performed in triplicate.

Optical microscopy images were registered using a Zeiss Scope A1 digital microscope equipped with a Canon camera (Taiwan).

IR spectra were performed using an Interspec 200-X FTIR equipment from Interspectrum in transmittance mode in the region $4000-400 \mathrm{~cm}^{-1}$. Collagen samples were prepared for IR measurements by using a manual hydraulic press to form $\mathrm{KBr}$ pellets.

The in vitro release of piroxicam from the tested formulations was performed using a sandwich device adapted to a paddle dissolution equipment, as previously detailed [28]. The concentration of piroxicam in each sample was investigated by UV spectroscopy at its maximum absorbance corresponding to a wavelength of $353 \mathrm{~nm}$ and using the standard calibration curve $\left(\mathrm{A}_{1 \%}^{1 \mathrm{~cm}}=479\right)$. The cumulative released drug percentage was then assessed. The kinetic data were fitted with the power law model (equation (3)) and its particular cases, Higuchi $(n=0.5)$ and zero-order $(n=1)$ models, and the drug release mechanism was set.

$$
\frac{m_{t}}{m_{\infty}}=k \times t^{n}
$$

where $m_{t} / m_{\infty}$ is the fractional release of the drug at time $t, k$ is the kinetic constant, and $n$ is the release exponent showing the drug release mechanism. The experiments were conducted in triplicate.

\section{Results}

Figure 1 presents the results obtained for water absorption experiments. The collagen matrices should possess proper water uptake abilities allowing the biological fluid penetration into the spongious structure and consecutively the drug diffusion within the swollen polymeric network. The obtained data suggest that the amount of piroxicam does not affect the water absorption capacity. At the same time, as expected, the water absorption is increasing in time, being $100 \%$ after 24 hours.

The enzymatic collagen degradation measurements as presented in Figure 2 revealed that piroxicam addition, as consequence, decreases the sample degradation. However, after more than 8 hours in collagenase solution, the samples disintegrate, even if they are not completely degraded. The 


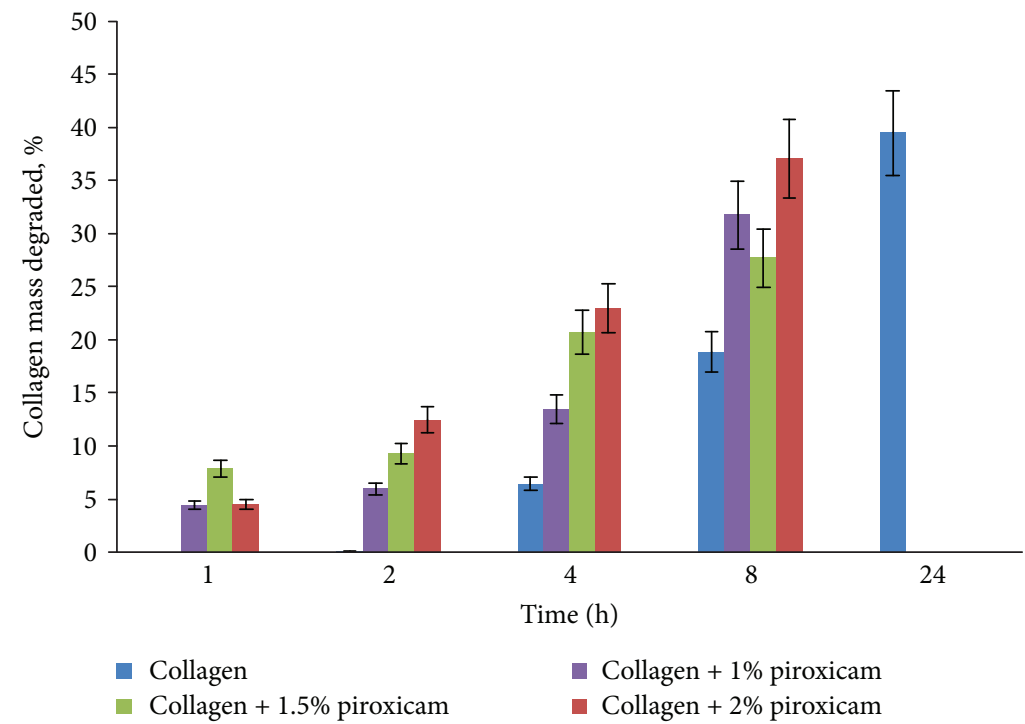

Figure 2: Enzymatic degradation of piroxicam sponges.

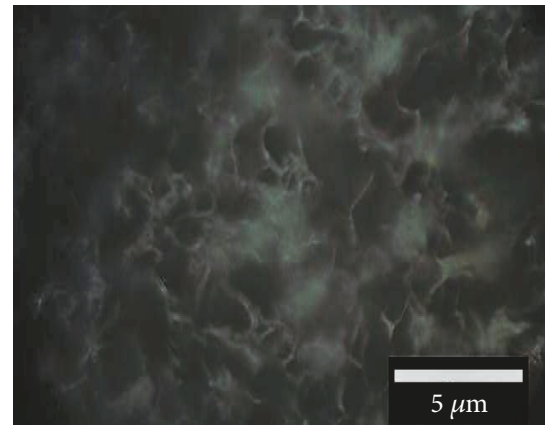

(a)

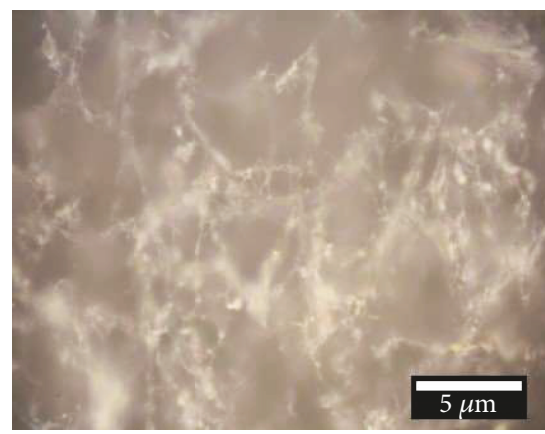

(c)

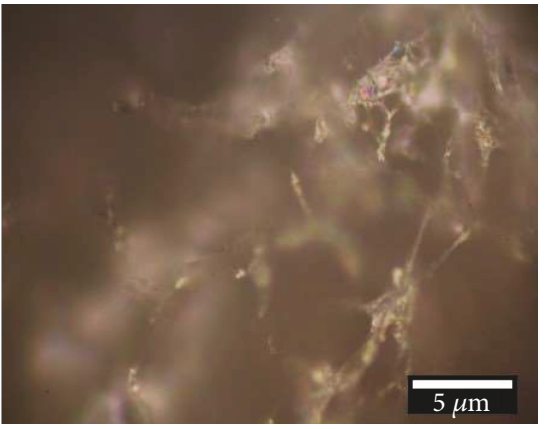

(b)

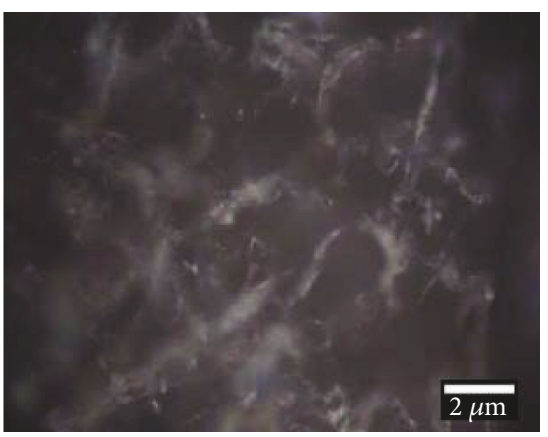

(d)

FiguRe 3: Optical microscopy images for collagen sponge (a) (100x), 1\% piroxicam collagen (b) (50x), 1.5\% piroxicam collagen (c) (50x), and $2 \%$ piroxicam collagen $(\mathrm{d})(100 \mathrm{x})$.

sponge degradation is relatively slow in the beginning (5-10\% in the first two hours). After 8 hours and before disintegration, around $30 \%$ of the samples are degraded suggesting that such kind of materials could be useful in oromaxillofacial surgery.

The optical microscopy images (Figure 3) displayed a fibrillar structure with interconnected pores. In all obtained sponges, the light spots prove the piroxicam presence.

The presence of the piroxicam in the collagen sponges was certified also by the IR spectra. Table 1 lists the assignments for the main absorption peaks obtained for the infrared spectra recorded. As expected, the IR spectra were similar as the characteristic peaks for the main vibrations are the same for collagen and for piroxicam. Nevertheless, some wavenumber shifts were present.

All the above analyses indicate that the designed collagen sponges present adequate properties as drug release supports. Thus, the collagen-piroxicam sponges were further analyzed from the kinetic point of view. 
TABLE 1: FTIR spectra peak position and assignments for collagen sponges.

\begin{tabular}{|c|c|c|c|c|}
\hline \multirow[b]{2}{*}{ Assignment } & \multicolumn{4}{|c|}{ Wavenumber $(1 / \mathrm{cm})$} \\
\hline & $\begin{array}{c}\text { Collagen } \\
\text { sponge }\end{array}$ & $\begin{array}{l}\text { Collagen }+0.5 \% \\
\text { piroxicam sponge }\end{array}$ & $\begin{array}{l}\text { Collagen }+1 \% \\
\text { piroxicam sponge }\end{array}$ & $\begin{array}{l}\text { Collagen }+1.5 \% \\
\text { piroxicam sponge }\end{array}$ \\
\hline \multicolumn{5}{|l|}{$\mathrm{N}-\mathrm{H}$ stretch $\left(v_{\mathrm{NH}}\right)$ of amide $\mathrm{A}[29,30]$} \\
\hline $\begin{array}{l}\text { Hydrogen bonding of the N-H group with a carbonyl } \\
\text { group of the peptide chain [29] }\end{array}$ & 3540 & 3569 & 3552 & 3550 \\
\hline $\begin{array}{l}\mathrm{CH}_{2} \text { asymmetrical stretch }\left(v_{a s \mathrm{CH} 2}\right) \text { by amide } \mathrm{B} \text { band } \\
{[29,30]}\end{array}$ & 3017 & 3008 & 3016 & 3007 \\
\hline $\begin{array}{l}\mathrm{C}-\mathrm{O} \text { stretching vibration }\left(v_{\mathrm{CO}}\right)[29] \\
\text { Amide I C=O stretching }[30,31]\end{array}$ & 1681 & 1681 & 1680 & 1680 \\
\hline $\begin{array}{l}\text { Hydrogen bond between N-H stretch }\left(v_{\mathrm{NH}}\right) \text { and C-O } \\
\left(v_{\mathrm{CO}}\right)[29]\end{array}$ & 1607 & 1606 & 1608 & 1610 \\
\hline \multicolumn{5}{|l|}{ Helical structure of collagen [29] } \\
\hline $\begin{array}{l}\text { Stretching vibration of the C-N group [29] } \\
\mathrm{C}=\mathrm{N} \text { stretching of piroxicam [31] }\end{array}$ & 1494 & 1499 & 1499 & 1496 \\
\hline \multicolumn{5}{|l|}{$\mathrm{CH}_{2}$ deformation $\left(\delta_{\mathrm{CH} 2}\right)[32]$} \\
\hline $\begin{array}{l}\mathrm{CH}_{3} \text { bend }\left(\delta_{\mathrm{CH} 3}\right)[32] \\
\mathrm{CH}_{2} \text { bending vibration }\left(\delta_{\mathrm{CH} 2}\right)[30]\end{array}$ & 1443 & 1441 & 1443 & 1443 \\
\hline $\mathrm{CH}_{2}$ group wagging vibration [29] & 1376 & 1379 & 1387 & 1380 \\
\hline $\mathrm{NH}$ deformation of amide III $\left(\delta_{\mathrm{NH}}\right)[32]$ & 1274 & 1274 & 1273 & 1275 \\
\hline Hydrogen bonding of $\mathrm{N}-\mathrm{H}$ bending $[29,30]$ & 1241 & 1237 & 1240 & 1240 \\
\hline $\begin{array}{l}\text { NH deformation of amide III }\left(\delta_{\mathrm{NH}}\right)[32] \\
S=O \text { asymmetric stretching [31] }\end{array}$ & 1191 & 1192 & 1189 & 1190 \\
\hline Ester bond [29] & 1113 & 1113 & 1115 & 1113 \\
\hline $\begin{array}{l}v(\mathrm{C}-\mathrm{O}), v(\mathrm{C}-\mathrm{O}-\mathrm{C}) \text { of carbohydrate moieties (collagen) } \\
{[32]}\end{array}$ & 1062 & 1063 & 1062 & 1063 \\
\hline Skeletal stretching vibrations [30] & 899 & 899 & 900 & 900 \\
\hline
\end{tabular}

TABLE 2: Kinetic parameters and correlation coefficients specific to power law model, correlation coefficients specific to Higuchi and zeroorder models, and drug release percentage.

\begin{tabular}{lcccccc}
\hline $\begin{array}{l}\text { Collagen-piroxicam } \\
\text { matrices (\% of piroxicam) }\end{array}$ & $\begin{array}{c}\text { Kinetic constant } \\
\left(1 / \mathrm{min}^{\mathrm{n}}\right)\end{array}$ & Release exponent & \multicolumn{2}{c}{ Correlation coefficient } & Drug release \\
\hline 1 & 0.11 & 0.39 & 0.9811 & 0.9716 & 0.8761 & 87.44 \\
1.5 & 0.12 & 0.38 & 0.9860 & 0.9755 & 0.8822 & 96.24 \\
2 & 0.10 & 0.41 & 0.9892 & 0.9831 & 0.9009 & 91.33 \\
\hline
\end{tabular}

From Table 2, it can be seen that the power law model describes well the drug release (correlation coefficient $>0.98$, being higher than the ones specific to Higuchi and zeroorder models).

The piroxicam release from the designed formulations showed an anomalous drug transport kinetic mechanism, the values obtained for the release exponent being smaller than 0.5 .

Figure 4 reveals typical biphasic drug release profiles, with an important piroxicam burst release effect in the first 30 minutes for the collagen matrices with $1 \%, 1.5 \%$, and $2 \%$ piroxicam, ensuring an inflammation rapid diminution, followed by a prolonged release over the next hours of experiments. The obtained values for the release exponent $(<0.5)$ revealed a complex release mechanism including swelling, diffusion, and erosion [28, 33].
Corroborating drug release results with those of collagenase degradation, it can be affirmed that before the sponge disintegration the drug is almost completely released. Moreover, depending on where these materials will be used, the fact that they absorb water suggests that they can absorb oral liquids or sanguinolent liquids and thus reducing the inflammation and the hematoma risk.

\section{Conclusions}

This study presents new collagen-based materials for biomedical applications, especially in dentistry. These new materials, collagen-based spongy materials, obtained by the lyophilization method, were characterized by various techniques like optical microscopy, IR spectroscopy, water 


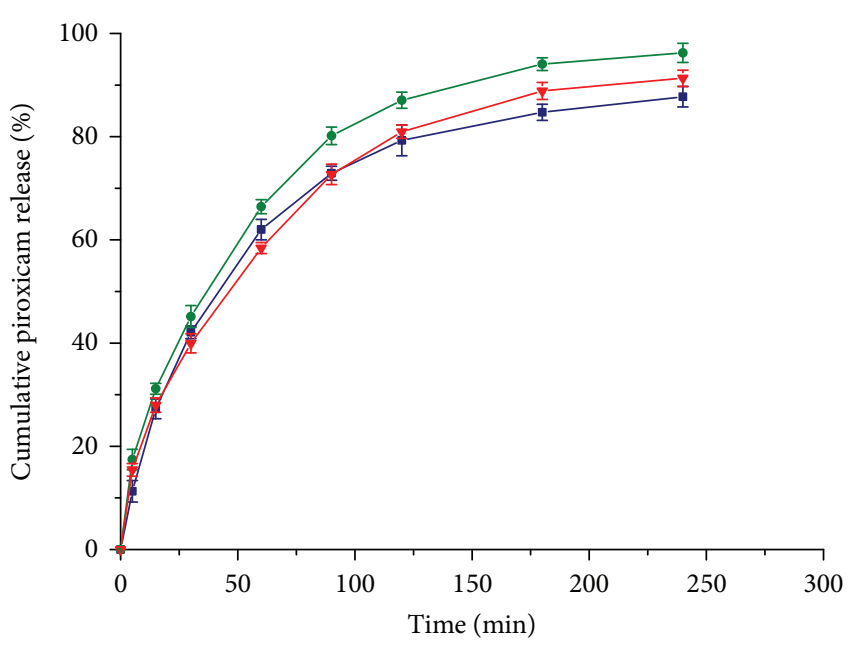

Figure 4: Cumulative release profiles of piroxicam from collagen matrices versus time: $1 \%$ piroxicam (blue square), $1.5 \%$ piroxicam (green circle), and $2 \%$ piroxicam (red triangle) $(n=3)$.

absorption, enzymatic degradation, and in vitro release kinetics.

The results obtained concerning the hydrolysis and enzymatic degradation showed the inhibitor role of the cross-linking agent, while the piroxicam presence determines an increasing sponge degradation under collagenase leading, at the end, to the sponge disintegration.

The kinetic profiles determined for piroxicam release suggest biphasic drug release profiles whereas the obtained values for the release exponent $(<0.5)$ revealed a complex release mechanism including swelling, diffusion, and erosion.

The results obtained suggest that, in the near future, piroxicam-collagen-based biomaterials would easily represent a viable and modern solution to treat various types of wound that occurs in oromaxillofacial surgery, cumulating the best properties of collagen and the NSAIDs.

\section{Data Availability}

All the supporting results are presented in the article.

\section{Conflicts of Interest}

The authors declare that there is no conflict of interest regarding the publication of this paper.

\section{Acknowledgments}

This paper was financially supported by "Carol Davila" University of Medicine and Pharmacy through Contract no. 23PFE/17.10.2018 funded by the Ministry of Research and Innovation within PNCDI III, Program 1-2013, Development of the National RD System, Subprogram 1.2-Institutional Performance-RDI excellence funding projects.

\section{References}

[1] V. Andreu and M. Arruebo, "Current progress and challenges of nanoparticle-based therapeutics in pain management," Journal of Controlled Release, vol. 269, pp. 189-213, 2018.

[2] R. Wardhan and J. Chelly, "Recent advances in acute pain management: understanding the mechanisms of acute pain, the prescription of opioids, and the role of multimodal pain therapy," F1000 Research, vol. 6, p. 2065, 2017.

[3] M. A. Attia, I. el-Gibaly, S. E. Shaltout, and G. N. Fetih, "Transbuccal permeation, anti-inflammatory activity and clinical efficacy of piroxicam formulated in different gels," International Journal of Pharmaceutics, vol. 276, no. 1-2, pp. 11-28, 2004.

[4] W. Badri, K. Miladi, Q. A. Nazari, H. Greige-Gerges, H. Fessi, and A. Elaissari, "Encapsulation of NSAIDs for inflammation management: overview, progress, challenges and prospects," International Journal of Pharmaceutics, vol. 515, no. 1-2, pp. 757-773, 2016.

[5] S. Mohammad, V. Singh, P. Wadhwani, H. P. Tayade, and O. K. Rathod, "Sublingual piroxicam in the management of postoperative pain after surgical removal of impacted mandibular third molar," Indian Journal of Dental Research, vol. 23, no. 6, pp. 839-840, 2012.

[6] C. Pereira-Leite, C. Nunes, and S. Reis, "Interaction of nonsteroidal anti-inflammatory drugs with membranes: in vitro assessment and relevance for their biological actions," Progress in Lipid Research, vol. 52, no. 4, pp. 571-584, 2013.

[7] P. A. K. Trindade, F. P. M. Giglio, B. L. Colombini-Ishikiriama et al., "Comparison of oral versus sublingual piroxicam during postoperative pain management after lower third molar extraction," International Journal of Oral and Maxillofacial Surgery, vol. 40, no. 3, pp. 292-297, 2011.

[8] P. J. Desjardins, "Analgesic efficacy of piroxicam in postoperative dental pain," The American Journal of Medicine, vol. 84, no. 5, pp. 35-41, 1988.

[9] J. J. O'Hanlon, G. McCleane, and T. Muldoon, "Preoperative application of piroxicam gel compared to a local anaesthetic field block for postoperative analgesia," Acta Anaesthesiologica Scandinavica, vol. 40, no. 6, pp. 715-718, 1996.

[10] R. L. Sheridan and R. G. Tompkins, "Skin substitutes in burns," Burns, vol. 25, no. 2, pp. 97-103, 1999.

[11] J. A. M. Ramshaw, Y. Y. Peng, V. Glattauer, and J. A. Werkmeister, "Collagens as biomaterials," Journal of Materials Science: Materials in Medicine, vol. 20, no. S1, pp. 3-8, 2009.

[12] J. Habermehl, J. Skopinska, F. Boccafoschi et al., "Preparation of ready-to-use, stockable and reconstituted collagen," Macromolecular Bioscience, vol. 5, no. 9, pp. 821-828, 2005.

[13] T. Muthukumar, P. Prabu, K. Ghosh, and T. P. Sastry, "Fish scale collagen sponge incorporated with Macrotyloma uniflorum plant extract as a possible wound/burn dressing material," Colloids and Surfaces B: Biointerfaces, vol. 113, pp. 207212, 2014.

[14] R. Nair, M. Sevukarajan, T. Mohammed, C. K. Badivaddin, and A. Kumar, "Collagen based drug delivery systems: a review," Journal of Innovation Trends in Pharmaceutical Science, vol. 1, pp. 288-304, 2010.

[15] H. L. Wang and R. L. Mac Neil, "Guided tissue regeneration," Dental Clinics of North America Journal, vol. 42, pp. 505-522, 1998. 
[16] R. Khan and M. H. Khan, "Use of collagen as a biomaterial: an update," Journal of Indian Society of Periodontology, vol. 17, no. 4, pp. 539-542, 2013.

[17] M. G. Patino, M. E. Neiders, S. Andreana, B. Noble, and R. E. Cohen, "Collagen as an implantable material in medicine and dentistry," Journal of Oral Implantology, vol. 28, no. 5, pp. 220-225, 2002.

[18] M. Akashi, M. Kishimoto, J. Kusumoto, K. Yakushijin, H. Matsuoka, and T. Komori, "Delayed socket healing after dental extraction in patients undergoing myelosuppressive chemotherapy for hematological malignancy: incidence and risk factors," Journal of Oral and Maxillofacial Surgery, vol. 76, no. 10, pp. 2057-2065, 2018.

[19] N. Joshi, S. Mathew, J. V. George, S. Hegde, S. Bhandi, and K. S. Madhu, "Comparative evaluation of the efficacy of two modes of delivery of Piroxicam (Dolonex ${ }^{\circledR}$ ) for the management of postendodontic pain: a randomized control trial," Journal of Conservative Dentistry, vol. 19, no. 4, pp. 301-305, 2016.

[20] S. Mansuri, P. Kesharwani, K. Jain, R. K. Tekade, and N. K. Jain, "Mucoadhesion: a promising approach in drug delivery system," Reactive and Functional Polymers, vol. 100, pp. 151-172, 2016.

[21] A. Banks, "Innovations in postoperative pain management: continuous infusion of local anesthetics," AORN Journal, vol. 85, no. 5, pp. 904-918, 2007.

[22] H.C. P. M. Caracas, J. V.B. Maciel, P.M. R.e.S. Martins, M. M. G. de Souza, and L. C. Maia, "The use of lidocaine as an antiinflammatory substance: a systematic review," Journal of Dentistry, vol. 37, no. 2, pp. 93-97, 2009.

[23] G. Mariappan, B. P. Saha, L. Sutharson et al., "Analgesic, anti-inflammatory, antipyretic and toxicological evaluation of some newer 3-methyl pyrazolone derivatives," Saudi Pharmaceutical Journal, vol. 19, no. 2, pp. 115-122, 2011.

[24] R.Constantin Barbaresso, I. Rău, R. GabrielaZgârian, A. Meghea, and M. Violeta Ghica, "Niflumic acid-collagen delivery systems used as anti-inflammatory drugs and analgesics in dentistry," Comptes Rendus Chimie, vol. 17, no. 1, pp. 12-17, 2014.

[25] S.-T. Li, "Biologic biomaterials: tissue-derived biomaterials (collagen)," in Biomaterials: Principles and Applications, J. B. Park, Ed., p. 127, CRC Press, Boca Raton, FL, USA, 2002.

[26] M. G. Albu, Collagen Gels and Matrices for Biomedical Applications, Lambert Academic Publishing, Saarbrücken, Germany, 2011.

[27] M. G. Albu, I. Titorencu, and M. V. Ghica, “Collagen-based drug delivery systems for tissue engineering," in Biomaterials Applications for Nanomedicine, R. Pignatello, Ed., pp. 333-334, INTECHOpen Access Publisher, 2011.

[28] M. Ghica, M. Albu Kaya, C.-E. Dinu-Pîrvu, D. Lupuleasa, and D. Udeanu, "Development, optimization and in vitro/in vivo characterization of collagen-dextran spongious wound dressings loaded with flufenamic acid," Molecules, vol. 22, no. 9, p. 1552, 2017.

[29] T. Riaz, R. Zeeshan, F. Zarif et al., "FTIR analysis of natural and synthetic collagen," Applied Spectroscopy Reviews, vol. 53, no. 9, pp. 703-746, 2018.

[30] V. Perez-Puyana, A. Romero, and A. Guerrero, "Influence of collagen concentration and glutaraldehyde on collagen-based scaffold properties," Journal of Biomedial Materials Research Part A, vol. 104, no. 6, pp. 1462-1468, 2016.

[31] M. K. Trivedi, S. Patil, H. Shettigar, K. Bairwa, and S. Jana, "Effect of biofield treatment on spectral properties of paracetamol and piroxicam," Chemical Sciences Journal, vol. 6, no. 3, 2015.
[32] K. Belbachir, R. Noreen, G. Gouspillou, and C. Petibois, "Collagen types analysis and differentiation by FTIR spectroscopy," Analytical and Bioanalytical Chemistry, vol. 395, no. 3, pp. 829-837, 2009.

[33] D. Narayanan, M. G. Geena, H. Lakshmi, M. Koyakutty, S. Nair, and D. Menon, "Poly-(ethylene glycol) modified gelatin nanoparticles for sustained delivery of the antiinflammatory drug ibuprofen-sodium: an in vitro and in vivo analysis," Nanomedicine: Nanotechnology, Biology and Medicine, vol. 9, no. 6, pp. 818-828, 2013. 


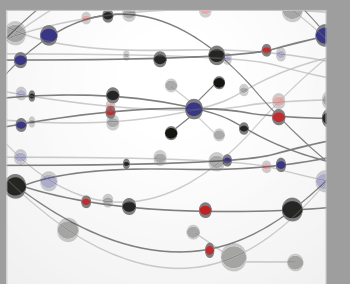

The Scientific World Journal
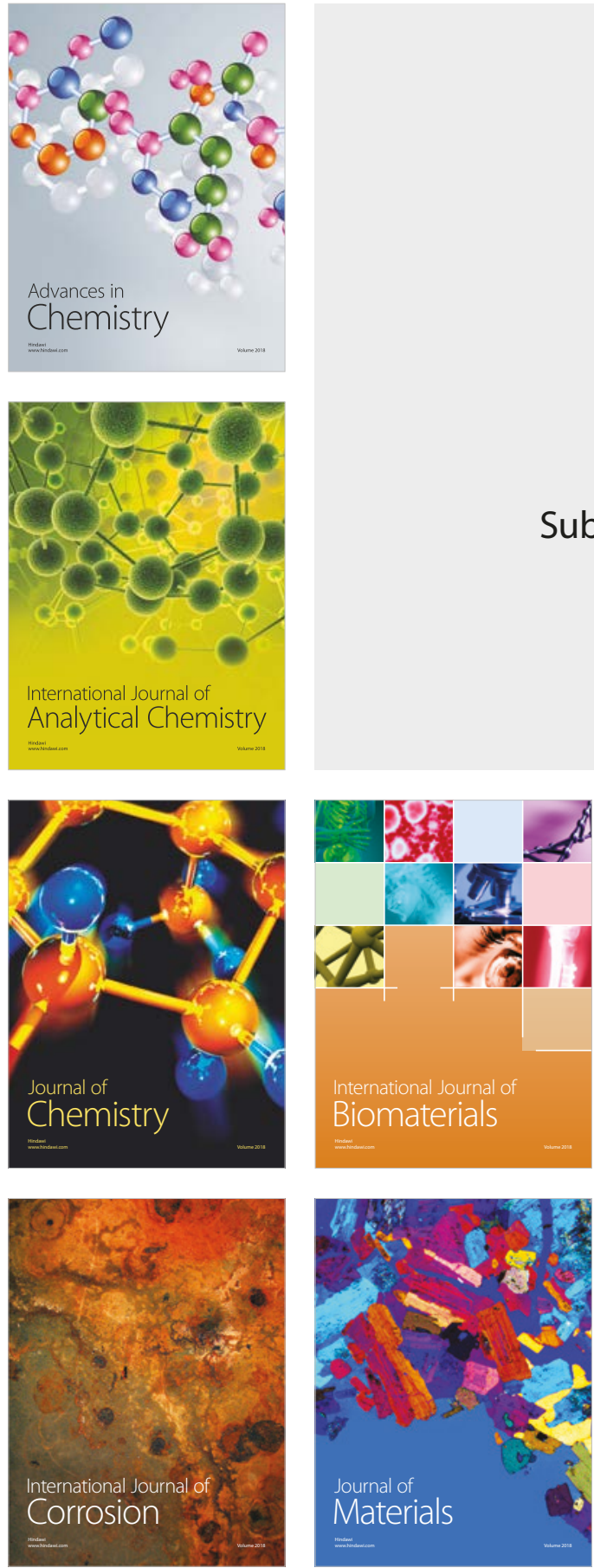

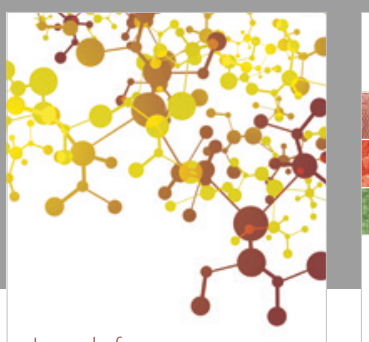

Journal of

Applied Chemistry
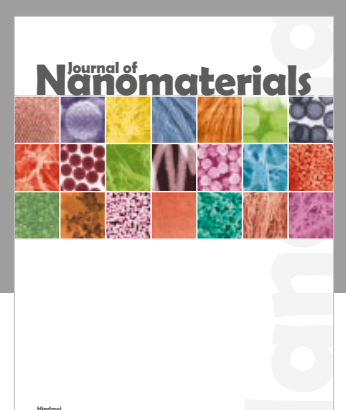

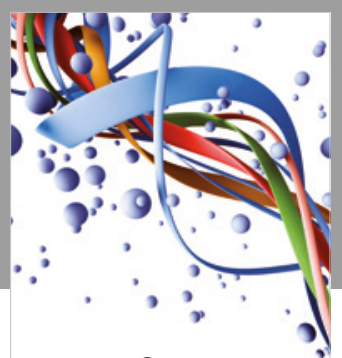

Scientifica

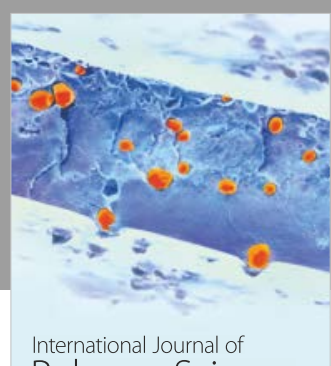

Polymer Science

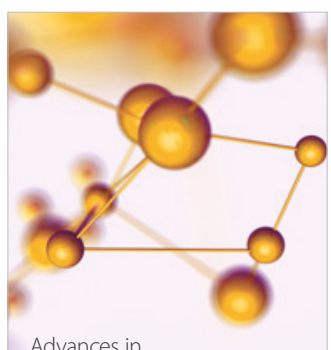

Physical Chemistry
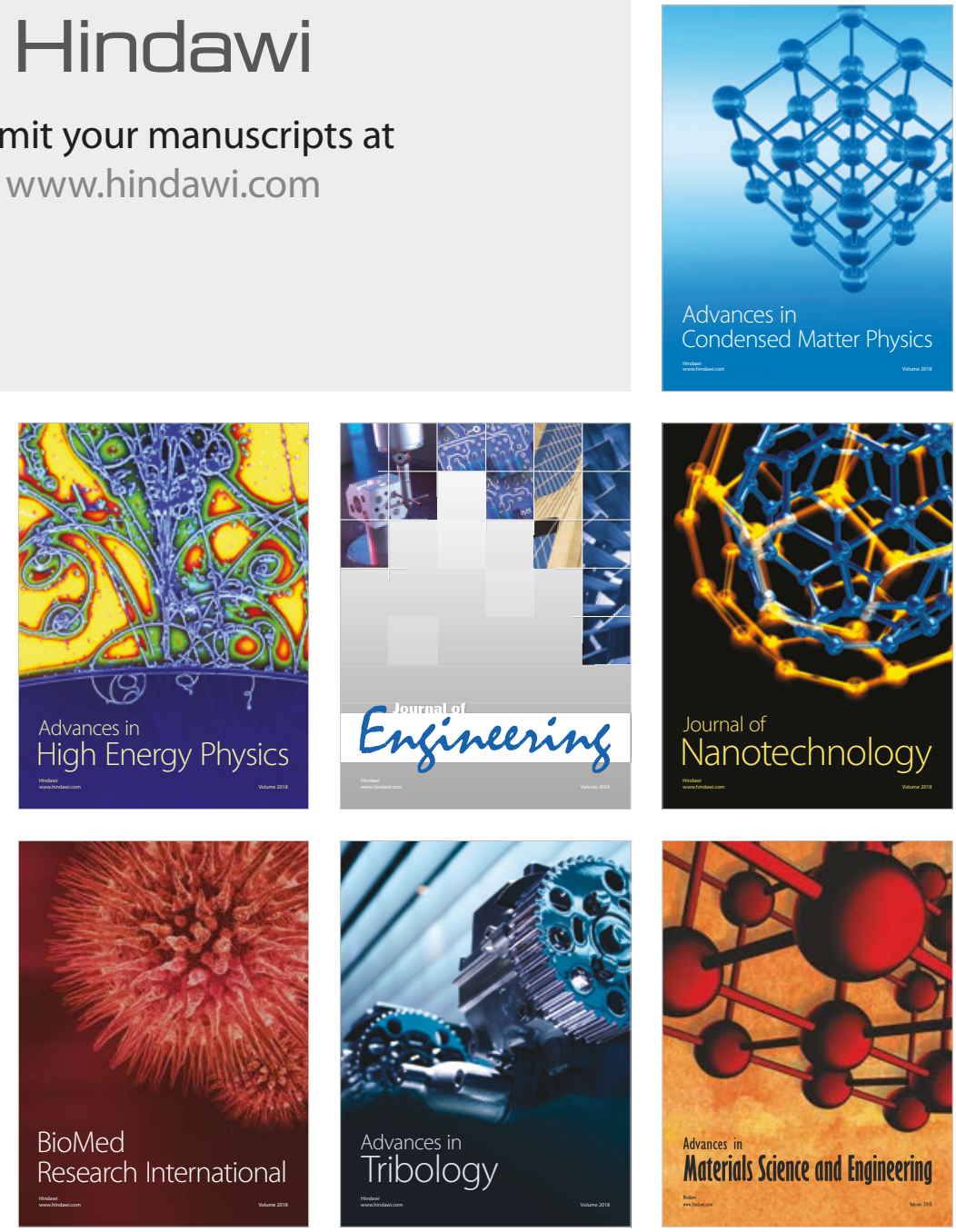